АНАЛІЗ ОСНОВНИХ ЧИННИКІВ РОЗВИТКУ СУЧАСНОГО МАРКЕТИНГУ ANALYSIS OF THE MAIN FACTORS OF MODERN MARKETING DEVELOPMENT

УДК 339.138: 519.876.5

https://doi.org/10.32843/bses.59-18

\section{Гнот T.B.}

аспірант касредри

економічної кібернетики

Національний університет біоресурсів

і природокористування України

\section{Hnot Taras}

National University of Life

and Environmental Sciences of Ukraine
Сучасний світ характеризується дуже швидкими змінами, активним технологічним розвитком та значною невизначеністю. Для досягнення успіху на ринку маркетологам необхідно правильно вибирати стратегію, налагоджувати контакти з клієнтами, використовувати нові інструменти та технології маркетингу й бути хоча б на крок попереду конкурентів. Серед великої кількості чинників, що впливають на розвиток маркетингу, ми виділяємо такі три групи: технологічні (розвиток інтернет-технологій, Big Data, Data Science, соціальні мережі), соціально-економічні (нерівність доходів та різноманіття), геополітичні (вільна торгівля та зміна клімату). Сучасні технологіі дають можливість компаніям спілкуватися безпосередньо зі споживачами, збирати досить багато інсрормації про них, аналізувати інсрормацію та використовувати ії для розвитку продуктів і подальшої взаємодії з клієнтами. Завдяки цьому змінюються підходи до маркетингу: від маркетингу як збутової діяльності до маркетингу як системи взаємовідносин зі споживачами. Впровадження сучасних технологій, удосконалення логістики та розширення спектру послуг сприяли спрощенню міжнародної торгівлі та посиленню глобальної конкуренції. Ключові слова: маркетинг, Інтернет, клієнт, технології, тендениії.

Современный мир характеризуется очень быстрыми изменениями, активным техно- логическим развитием и значительной неопределенностью. Для достижения успеха на рынке маркетологам необходимо правильно выбирать стратегию, налаживать контакты с клиентами, использовать новые инструменты и технологии маркетинга и быть хотя бы на шаг впереди конкурентов. Среди большого количества фракторов, влияющих на развитие маркетинга, мы выделяем такие три группы: технологические (развитие интернет-технологий, Big Data, Data Science, социальные сети), социальноэкономические (неравенство доходов и разнообразие), геополитические (свободная торговля и изменение климата). Современные технологии дают возможность компаниям общаться непосредственно с потребителями, собирать достаточно много инфрормации о них, анализировать информацию и использовать ее для развития продуктов и дальнейшего взаимодействия с клиентами. Благодаря этому меняются подходы к маркетингу: от маркетинга как сбытовой деятельности к маркетингу как системы взаимоотношений с потребителями. Внедрение современных технологий, совершенствование логистики и расширение спектра услуг способствовали упрощению международной торговли и усилению глобальной конкуренции.

Ключевые слова: маркетинг, Интернет, клиент, технологии, тенденции.

The modern world is characterized by very rapid changes, active technological development, and significant uncertainty. The main commodity in the modern economy is the products of intellectual activity. Information technology is becoming a basic tool for such products, as well as creating an opportunity for direct active communication of all market participants, which significantly increases competition. To succeed in today's market, marketers need to choose the right strategy, establish contacts with customers, use modern marketing tools and technologies, and be at least one step ahead of competitors. Among the many factors influencing the development of marketing, we distinguish the following three groups: technological - the development of Internet technologies, Big Data, Data Science, social networks, socio-economic - income inequality and diversity, geopolitical - free trade and climate change. The development of Internet technologies has significantly changed approaches to marketing. Thanks to the Internet, it has become possible to establish direct contact with the target audience and personalize the offer for customers. Another technological trend is the development of communication technologies, which helps to establish close contacts with customers; increasing storage capacity; increase the speed of calculations, which allows companies to analyze customer data. As a result of these processes, there was a rapid growth of available customer data, the so-called Big Data. The availability of Big Data and the advancement of technology have contributed to the application of Data Science in the economy in general and in marketing in particular. Already, marketing is actively using algorithms and technologies of Data Science in the personalization of advertising, targeting ads and advertising, in the analysis of personal data of customers and their segmentation in real-time, in the analysis of audience mood, in intelligent customer service, and many other processes. Modern technologies allow companies to communicate directly with consumers, collect a lot of information about them, analyze information, and use it for product development and further interaction with customers. Due to this, approaches to marketing are changing: from marketing as a sales activity to marketing as a system of relationships with consumers. The introduction of modern technologies improved logistics and expanded the range of services have led to the simplification of international trade and increased global competition.

Key words: marketing, Internet, client, technologies, tendencies.

Постановка проблеми. Сучасний світ характеризується дуже швидкими змінами, активним технологічним розвитком та значною невизначеністю. Основний товар у сучасній економіці - це продукти інтелектуальної діяльності. Інформаційні технології стають базовим інструментом для таких продуктів, а також створюють можливість для прямої активної комунікації всіх учасників ринку, що значно посилює конкуренцію. У результаті цього у клієнтів є дуже великий вибір товарів та послуг, досить простий доступ до них та значна цінова диверсифрікація. Все це приводить до високих вимог до сучасного маркетингу. Для досягнення успіху на сучасному ринку маркетологам необхідно правильно вибирати стратегію, налагоджувати контакти з клієнтами, використовувати сучасні інструменти та технології маркетингу й бути хоча б на крок попереду конкурентів.

Аналіз останніх досліджень і публікацій. Питанню розвитку маркетингу та дослідженню основних фракторів розвитку присвячена значна кількість праць. Зокрема, класичною літературою у маркетингу вже стали праці Ф. Котлера [1; 2]. Інноваційні підходи у маркетингу досліджу- 
ють С. Ілляшенко та М. Рудь [3; 4]. Дослідженню основних чинників розвитку маркетингу присвячені праці таких науковців, як М. Окландер [5], Т. Янковець, М. Вишневська [6], М. Діаконеску [7]. Питанню застосування сучасних методів та моделей у маркетинговій діяльності присвячено дослідження Н. Кулєшової [8], М. Негрей та Т. Гнота [9; 10]. Дослідженню сутності та місця інтернетмаркетингу в маркетинговій діяльності підприємства присвячено праці П. Каннана [11], С. Кінгснорта [12] та Л. Патрутіу-Балтеса [13].

Постановка завдання. Метою дослідження $€$ аналіз основних чинників розвитку сучасного маркетингу та оцінювання їх впливу на маркетингову діяльність компаній.

Виклад основного матеріалу дослідження. Глобалізація та швидкий розвиток інформаційних технологій приводять до суттєвої зміни всіх процесів в економіці. Маркетинг не є винятком. Сучасний маркетинг суттєво змінює не тільки фрункції, але й підходи до бізнес-процесів.

На розвиток маркетингу впливають багато елементів зовнішнього середовища, зокрема розвиток економіки, технології, інновації, зміна клімату, пандемія. Серед великої кількості чинників ми виділяємо такі три групи (рис. 1): технологічні, соціально-економічні, геополітичні.

Застосування нових технологій завжди справляло значний вплив на маркетинг. Поява газет дала змогу підприємцям отримати доступ до широкого кола споживачів завдяки друкованій рекламі. Поширення стаціонарних телеоронів покращило можливості комунікації компанії і клієнта. Розвиток Інтернету дав змогу компаніям вийти на новий рівень охоплення ринку та спілкування з клієнтами. Використання смарторонів зробило спілкування ще більш активним, а інформацію ще більш доступною. Виникнення соціальних мереж зробило компанії та їх продукти ще ближчими до споживача.

Розвиток інтернет-технологій суттєво змінив підходи до маркетингу. Завдяки Інтернету стали можливими установлення прямого контакту 3 цільовою аудиторією та персоналізація пропозиції для клієнтів. Під час застосування традиційних каналів зв'язку маркетинг працював з уявним пор- третом споживача й подавав інфрормацію таким чином, як, на думку маркетологів, було найбільш правильно й близько до потреб клієнта. Проте такий підхід часто був неефективним. Інтернет суттєво змінив ситуацію: зараз клієнти самі шукають інорормацію, яка їм потрібна, самі шукають потрібного виробника з відповідними їхнім бажанням ціною, якістю та іншими характеристикам товарів чи послуг. В такій ситуації компанії мають можливість максимально наблизитися до клієнта і створювати персональні пропозиції. Застосування сучасних інтернет-технологій створює для компаній ситуацію, в якій вони можуть давати індивідуальну інорормацію для всіх цільових аудиторій.

3 початку XXI століття доступ до Інтернету споживачів збільшився в рази (рис. 2). Відповідно, збільшилось залучення споживачів до діалогу 3 компанією. Клієнти тепер мають настільки великий вплив, що можуть вплинути не лише на самі товари та послуги, але й на всі процеси управління компанією. Так, свідоме споживання клієнтів приводить компанії до змін у технологіях, використання нових ресурсів (наприклад, recycled-технології та матеріали або технології, які зменшують викиди СО2). Думка клієнтів суттєво може змінити імідж компанії. Таким чином, у сучасному світі клієнти стають не просто покупцями товарів, але й значною групою впливу на компанію і ринок загалом. Це суттєво збільшує відповідальність компанії перед клієнтами і вимагає нових підходів до спілкування 3 ними, що суттєво змінює концепцію маркетингу.

У сучасному маркетингу спостерігається ще одна технологічна тенденція, а саме розвиток комунікаційних технологій, що сприяє встановленню тісних контактів із клієнтами; збільшення можливостей обсягів зберігання даних; збільшення швидкості обчислень, що дає змогу компаніям аналізувати дані клієнтів. У результаті цих процесів відбулося швидке зростання наявних даних про клієнтів, так званих Big Data.

Розвиток Інтернету, особливо в мобільних телефронах, привів до зростання можливості відстежувати поведінку клієнтів в Інтернеті. Використання фрайлів cookie для відстеження дає змогу компаніям негласно відстежувати поведінку клієнтів в

\begin{tabular}{|c|c|c|}
\hline Технологічні & $\begin{array}{l}\text { Соціально- } \\
\text { економічні }\end{array}$ & Геополітичні \\
\hline $\begin{array}{l}\text { - Розвиток інтернет- } \\
\text { технологій } \\
\text { - Big Data } \\
\text { • Data Science } \\
\text { - Соціальні мережі }\end{array}$ & $\begin{array}{l}\text { • Нерівність } \\
\text { доходів } \\
\text { • Різноманіття }\end{array}$ & $\begin{array}{l}\text { • Вільна торгівля } \\
\text { • Зміна клімату }\end{array}$ \\
\hline
\end{tabular}

Рис. 1. Основні чинники розвитку маркетингу 


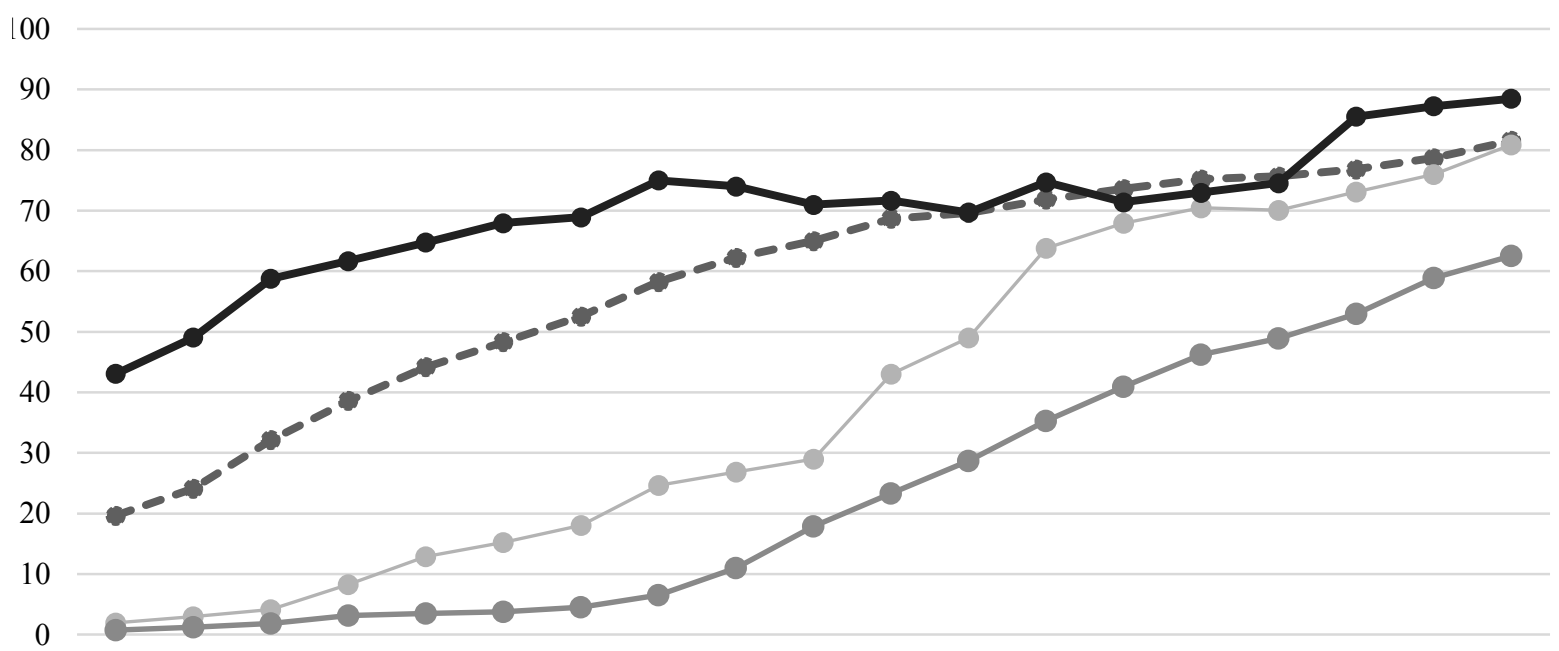

2000200120022003200420052006200720082009201020112012201320142015201620172018

- European Union $\quad \longrightarrow$ Russian Federation $\quad$ United States

Рис. 2. Індивідуальне використання Інтернету (\% населення) [14]

Інтернеті за рахунок особистої коноріденційності. Таке відстеження робить можливим більш персоналізовану рекламу. Зокрема, Facebook критикували за збір даних із соціальної мережі та із інших додатків для смартфонів.

Клієнти віддають перевагу персоналізованому підходу, оскільки це може задовольнити їх унікальні потреби та бажання. Проте недоліком такого підходу є втрата конфіденційності. Клієнти ставлять перед компаніями високі вимоги до конфріденційності та віддають перевагу персоналізованим пропозиціям. В результаті компаніям необхідно вибирати компроміс між персоналізацією та конфріденційністю.

Доступність Big Data та вдосконалення технологій сприяли застосуванню Data Science в економіці загалом і маркетинговій діяльності зокрема. Вже зараз маркетинг активно використовує алгоритми й технології Data Science у персоналізації реклами, орієнтуванні цільових оголошень та реклами, аналізі персональних даних клієнтів та їх сегментації в реальному часі, аналізі настроїв аудиторії, інтелектуальному обслуговуванні клієнтів та багатьох інших процесах. Хоча використання Data Science у маркетингу має ще недовготривалу історію, зміни вже суттєві, а в подальшому вони будуть ще більшими: розроблення кращих алго- ритмів, за допомогою яких може бути вдосконалений маркетинговий процес, що включатиме не тільки машинне навчання та нейронні мережі, але й широкий спектр інструментів зі статистики та інфрорматики.

Соціальні мережі стали важливими маркетинговими платформами. Кількість користувачів соціальних мереж активно зростає (табл. 1), що створює для компаній нові можливості для спілкування 3 клієнтами.

Використання соціальних мереж у маркетингу створює значні переваги для компанії, такі як зростання аудиторії, покращення зв'язку з клієнтами, збільшення відвідуваності веб-сайту, підвищене впізнавання бренду, генерування більшої кількості потенційних клієнтів, збільшення продажів і прибутків.

Відсутність компанії у соціальних мережах приводить до неповної маркетингової стратегії. Соціальні мережі сьогодні мають бути важливою складовою частиною маркетингових зусиль компанії.

Попри технологій, на маркетингові процеси також впливають соціально-економічні чинники. Нерівність доходів для економічного розвитку $€$ несприятливим фрактором. Проте для маркетингу за правильного підходу нерівність доходів може стати джерелом додаткових можливостей.

Таблиця 1

Кількість щомісячних активних користувачів найпопулярніших платорорм соціальних мереж [15]

\begin{tabular}{|c|c|c|c|c|c|}
\hline $\begin{array}{c}\text { Соціальна } \\
\text { мережа }\end{array}$ & $\begin{array}{c}\text { Кількість } \\
\text { користувачів }\end{array}$ & $\begin{array}{c}\text { Соціальна } \\
\text { мережа }\end{array}$ & $\begin{array}{c}\text { Кількість } \\
\text { користувачів }\end{array}$ & $\begin{array}{c}\text { Соціальна } \\
\text { мережа }\end{array}$ & $\begin{array}{c}\text { Кількість } \\
\text { користувачів }\end{array}$ \\
\hline Facebook & 2,37 млрд. & WeChat & 1 млрд. & LinkedIn & 303 млн. \\
\hline YouTube & 2 млрд. & Qzone & 572 млн. & Snapchat & 301 млн. \\
\hline WhatsApp & 1,5 млрд. & Tumblr & 371 млн. & Skype & 300 млн. \\
\hline Messenger & 1,3 млрд. & Twitter & 330 млн. & Pinterest & 291 млн. \\
\hline Instagram & 1 млрд. & Reddit & 330 млн. & Line & 217 млн. \\
\hline
\end{tabular}


Сегментування клієнтів і відповідні маркетингові зусилля можуть суттєво підвищити ефективність маркетингу.

Різноманіття населення часто стає причиною дискримінації, причому спостерігається тенденція збільшення масштабів цієї проблеми. Все більш поширена міграція людей із менш розвинутих країн у більш розвинені країни гарантує, що в більш розвинених країнах обов'язково буде «нижчий клас» протягом багатьох років, а іммігранти, ймовірно, будуть більш різноманітними. Наприклад, США зараз стикаються зі значним імміграційним тиском 3 Латинської Америки, а Європа намагається з'ясувати, як асимілювати мусульман із Близького Сходу та Північної Афррики. В маркетинговій діяльності компаніям може бути доцільно здійснювати дискримінацію у сорері обслуговування споживачів, які походять із груп, які в середньому $є$ менш вигідними, навіть якщо ці споживачі однакової якості, а також демонструють еквівалентні об'єктивні показники якості.

Геополітичні фрактори, що впливають на економіку, також мають великий вплив на маркетинг. Хоча розвинені економіки світу перейшли до вільної, геополітичні процеси часто суттєво змінюють умови й порядок торгівлі. Такі процеси, як Brexit, введення тарифів адміністрацією Д. Трампа, пандемія, спричинена COVID-19, суттєво впливають не тільки на міжнародні продажі, але й на ланцюг поставок, оскільки фрірми, що виробляють продукцію через національні кордони, потребують необмеженого руху через ці межі. Міжнародний маркетинг має негативний вплив, коли ціноутворення (отже, й попит) змінюється непередбаченими способами. Загалом упровадження сучасних технологій, удосконалення логістики та розширення спектру послуг спричинили спрощення міжнародної торгівлі та посилення глобальної конкуренції.

Клімат змінюється з безпрецедентною в історії людства швидкістю. Це перш за все впливає на сільське господарство. Відповідно, змінюються структури попиту та пропозиції у всьому світі. Маркетологи повинні постійно брати це до уваги, а також прийняти припущення, що ринок є системою динамічної нерівноваги. Зміна клімату суттєво впливає на маркетинг, оскільки традиційні способи часто стають неможливими, а маркетологам необхідно шукати нові шляхи розвитку. Внаслідок зміни клімату відбувається зростання екологічного маркетингу та пропозицій, що підтримують сталий розвиток.

Висновки з проведеного дослідження. Узагальнюючи викладене, зазначаємо, що сьогодні відбувається розширення сорери «традиційного» маркетингового мислення. Цьому сприяють такі чинники: технологічні, соціально-економічні та геополітичні. Відбувається трансформація традиційних маркетингових підходів до нових, які засто- совують сучасні інфрормаційні технології, соціальні мережі та інструментарій Data Science, використовуються нерівність доходів та диореренціація суспільства, сучасні інновації, умови вільної торгівлі, враховуються вимоги щодо дбайливого ставлення до навколишнього середовища.

\section{БІБЛІОГРАФІЧНИЙ СПИСОК:}

1. КотлерФ., ТэорТ.Р., Виноградова Т.В., ЦарукЛ.Л. Новые маркетинговые технологии. Методики создания гениальных идей. Нева, 2004.

2. Котлер Ф., Келлер К.Л. Маркетинг менеджмент. 15-е изд. Санкт-Петербург : Питер, 2018.

3. Ілляшенко С., Рудь М. Новітні види маркетингу в умовах випереджаючого розвитку: еволюція, сутність, умови застосування. Науковий вісник Ужгородського національного університету. 2019. № 2 (24). С. 37-42.

4. Ілляшенко С., Рудь М. Підходи до створення маркетингових інновацій у системі комплексу маркетингу 4Р. Вісник ОНУ імені І. І. Мечникова. 2020. Т. 25. Вип. 1 (80). С. 121-129.

5. Oklander M.A., Oklander T.O.,Yashkina O.I. Marketing research trends: online panels and online communities. Marketing and Management of Innovations. 2018. № 1. P. 118-129.

6. Yankovets T., Vyshnevska M. Innovations and digital marketing: current trends of development. Evropský časopis ekonomiky a managementu. 2019.

7. Diaconescu M. Some considerations regarding the new trends in marketing approaches. Romanian Economic Journal. 2020. № 23 (77). P. 2-10.

8. Кулєшова Н. Аналіз сучасних методів та моделей формування маркетингової стратегії туристичних підприємств. Ефективна економіка. 2011. № 4.

9. Nehrey M., Hnot, T. Using recommendation approaches for ratings matrixes in online marketing. Studia Ekonomiczne. 2017. № 342. P. 115-130.

10. Негрей М., Гнот Т. Компаративний аналіз есрективності рекомендаційних систем в маркетингу. Вісник Хмельницького національного університету. Економічні науки. 2017. № 5. С. 278-286.

11. Kannan P.K. et al. Digital marketing: A framework, review and research agenda. International Journal of Research in Marketing. 2017. № 34 (1). P. 22-45.

12. Kingsnorth S. Digital marketing strategy: an integrated approach to online marketing. Kogan Page Publishers, 2019.

13. Patrutiu-Baltes L. Inbound Marketing-the most important digital marketing strategy. Bulletin of the Transilvania University of Brasov. Economic Sciences. 2016. Series V. № 9 (2). P. 61.

14. World Bank Open Data. URL: https://data.worldbank.org (дата звернення: 12.10.2020).

15. Appypie. URL: https://www.appypie.com (дата звернення: 12.10.2020).

\section{REFERENCES}

1. Kotler F., Keller K.L. (2018) Marketing-menedzhment [Marketing management]. Saint-Petersburg. (in Russian) 
2. Kotler F., Trias de Bez F. (2004) Novye marketingovye tekhnologii. Metodiki sozdaniya genial'nykh idey [New marketing technologies. Techniques for creating brilliant ideas]. Saint-Petersburg: Neva. (in Russian)

3. Illjashenko S., Rudj M. (2019) Novitni vydy marketynghu: evoljucija, sutnistj, umovy zastosuvannja [The latest types of marketing: evolution, essence, conditions of application]. Naukovyj visnyk Uzhghorodsjkogho nacionaljnogho universytetu, vol. 2 (24), pp. 37-42.

4. Illjashenko S., Rudj M. (2020) Pidkhody do stvorennja marketynghovykh innovacij u systemi kompleksu marketynghu 4R [Approaches to the creation of marketing innovations in the system of marketing complex 4P]. Visnyk ONU imeni I.I. Mechnykova, vol. 25, no. 1 (80), pp. 121-129.

5. Oklander M., Oklander T., Yashkina O. (2018) Marketing research trends: online panels and online communities. Marketing and Management of Innovations, no. (1), pp. 118-129.

6. Yankovets T., Vyshnevska M. (2019). Innovations and digital marketing: current trends of development. Evropský časopis ekonomiky a managementu.

7. Diaconescu M. (2020). Some considerations regarding the new trends in marketing approaches. Romanian Economic Journal, no. 23 (77), pp. 2-10.

8. Kuljeshova N. (2011) Analiz suchasnykh metodiv ta modelej formuvannja marketynghovoji strateghiji turystychnykh pidpryjemst [Analysis of modern methods and models of formation of marketing strategy of tourist enterprises]. Efektyvna ekonomika, no. 4.

9. Nehrey M., Hnot T. (2017) Komparatyvnyj analiz efektyvnosti rekomendacijnykh system $v$ marketynghu [Comparative analysis of the effectiveness of recommendation systems in marketing]. Visnyk Khmeljnycjkogho nacionaljnogho universytetu. Ekonomichni nauky, no. 5, pp. 278-286.

10. Nehrey M., Hnot T. (2017) Using recommendation approaches for ratings matrixes in online marketing. Studia Ekonomiczne, no. 342, pp. 115-130.

11. Kannan P.K. et al. (2017) Digital marketing: A framework, review and research agenda. International Journal of Research in Marketing, t. 34, no. 1, pp. 22-45.

12. Kingsnorth S. (2019) Digital marketing strategy: an integrated approach to online marketing. Kogan Page Publishers.

13. Patrutiu-Baltes L. (2016) Inbound Marketing-the most important digital marketing strategy. Bulletin of the Transilvania University of Brasov. Economic Sciences. Series V, t. 9, no. 2, p. 61.

14. World Bank Open Data. Available at: https://data.worldbank.org (accessed 12 October 2020).

15. Appypie. Available at: https://www.appypie.com (accessed 12 October 2020). 